J. Amer. Soc. Hort. ScI. 116(5):888-893. 1991.

\title{
Citrus Fruit Sector Chimeras as a Genetic Resource for Cultivar Improvement
}

\author{
Kim D. Bowman ${ }^{1}$ and Frederick G. Gmitter, Jr. \\ Citrus Research and Education Center, University of Florida, Institute of Food and Agricultural \\ Sciences, 700 Experiment Station Road, Lake Alfred, FL 33850
}

\begin{abstract}
Gloria A. Moore
Fruit Crops Department, University of Florida, Institute of Food and Agricultural Sciences, Gainesville, FL 32611
\end{abstract}

\author{
Russell L. Rouseff \\ Citrus Research and Education Center, University of Florida, Institute of Food and Agricultural \\ Sciences, 700 Experiment Station Road, Lake Alfred, FL 33850
}

Additional index words. orange, grapefruit, mutation, breeding, ploidy, pest resistance, chromatography

\begin{abstract}
Citrus fruit with sector chimeras were collected in commercial packinghouses and from the field. Chimeric fruit from eight cultivars of sweet oranges [Citrus sinensis (L.) Osbeck], grapefruit (C. paradisi Macf.), tangelo (C. paradisi $\times C$. reticulate Blanco), and tangors (C. reticulate $\times$ C. sinensis) were found at a frequency of $0.009 \%$ to $0.271 \%$. Tetraploid plants obtained from one type of sector mutant (termed gigas) and albino plants obtained from another type of sector mutant confirmed that some genetic mutations observed in fruit rind can be recovered in nucellar seedlings. The gigas chimeras were identified as a source of citrus tetraploids. Several types of potentially useful sector mutants with altered rind color were observed, and plants were produced from some mutant sectors by developed seed or culture of aborted ovules. HPLC analysis of rind tissues from sectors of one chimeric fruit revealed substantial quantitative and qualitative differences in pigment composition. Propagation of plants from mutant sectors may yield cultivars with improved fruit color, altered maturation date, and reduced disease or mite susceptibility and may eventually lead to breeding of seedless triploid hybrids.
\end{abstract}

The phenomenon of fruit sector chimera, or fruit sectoring, has been observed among several citrus cultivars and is considered to be a negative attribute by growers, packers, and consumers. Lindgren and Sinclair (1941) reported that $0.1 \%$ to $0.2 \%$ of the fruit from 'Valencia' and navel oranges (C. sinensis), lemon [C. limon (L.) Burro. f.], and grapefruit (C. paradisi) had ridging or rind sectors. No thorough investigation of the phenomenon in citrus has been reported. Cyanide application during flower bud formation was found to increase the frequency of ridged sectors (Sinclair and Lindgren, 1943), and Lorsban (chlorpyrifos) may have a similar effect (M.L. Arpaia, personal communication). The effect of environmental factors on the production of citrus fruit chimeras is unknown.

Most important sweet orange and grapefruit scion cultivars are not the result of sexual hybridization in breeding programs, while many of the common cultivars have been produced by chance somatic mutations in previously existing selections (Hodgson, 1967; Mendel, 1981; Stewart et al., 1975). These facts, as well as the severe constraints on sexual hybridization in citrus (Frost and Soost, 1968; Soost and Cameron, 1975), have fueled interest in the generation and/or identification of favorable somatic mutations for development of new cultivars (Hearn, 1986; Hensz, 1981; Russo et al., 1981).

Received for publication 8 Aug. 1990. Florida Agr. Expt. Sta. J. Series no. R00949. We gratefully acknowledge the cooperation and assistance of W.G. Roe and Sons Co., Haines City Citrus Growers Assn., T. Zito, M.K. Wendell, T.H. Putnam, X.X. Deng, J. Bade, and X.B. Ling, with special thanks to W. Grierson for encouragement and advice. Part of this study was a portion of the dissertation research of K.D.B. Mention of trade names in this publication does not imply endorsement of products named nor criticism of similar ones not mentioned. The cost of publishing this paper was defrayed in part by the payment of page charges. Under postal regulations, this paper therefore must be hereby marked advertisement solely to indicate this fact.

'Present address: Dept. of Botany and Plant Sciences, Univ. of California, Riverside, CA 92521
Although there is little direct evidence, citrus fruit sector chimeras may be manifestations of genetic mutations or of somatic segregation (Cameron and Frost, 1968; Frost, 1943; Shamel, 1943; Toxopeus, 1933). If such mutations could be recovered, they would provide a valuable source of genetic variants for citrus breeding programs. Iwamasa et al. (1977) reported that plants grown from seeds that were produced within a yellow rind sector of 'Fukuhara' orange bore fruit with entirely yellow rinds. Plants produced from seeds within the normal orange sector of the same fruit bore normal, entirely orange fruit. This is the only instance where a fruit sector chimera in citrus has been reported to yield genetically altered plants.

The objectives of our study were to determine the kinds and frequencies of fruit sector chimeras in some common citrus cultivars and to evaluate the potential usefulness of these chimeras as a source of genetic mutations. We report here: 1) data on fruit sector chimera frequeney in eight citrus cultivars, 2) the identification of several kinds of potentially useful sector mutants, 3) HPLC characterization of rind pigment composition for one dark-orange-sectored fruit, 4) evidence that one common type of fruit sector chimera with thickened rind (gigas) is the result of polyploidization, 5) that tetraploid seedlings may be easily recovered from gigas sectors, and 6) that some red sector mutants produce albino seedlings.

\section{Materials and Methods}

Data on frequeney of fruit chimeras were collected at two commercial packinghouses near Lake Alfred, Fla., between Dec. 1988 and Apr. 1989 for eight cultivars: 'Pineapple', 'Hamlin', and 'Valencia' sweet oranges; 'Marsh' and 'Redblush' grapefruit; 'Orlando' tangelo; and 'Temple' and 'Murcott' tangors. Graders at citrus packinghouses separate fresh fruit into four quality categories: number 1 , number 2 , eliminations for juice production, and culls for discard (Soule and Grierson, 1986). 
Chimeric fruit for the frequency study were collected from eliminations and number 2 conveyers after preliminary observations indicated that most sectored fruit would be sorted into these categories by packinghouse operations. The few chimeric fruit that may have been sorted into number 1 and cull categories were not sampled in this study. Eliminations and number 2 fruit were combined during packinghouse operations for some cultivars; thus, separate data for the two categories could not be obtained. The total number of fruit sampled for each cultivar included fruit of all categories and was estimated to the nearest 1000 from packinghouse records and sample counts. All fruit with chimeric sectors were counted from the two grades during the sampling period and classified according to type of sector change. Some chimeric fruit with unusual sector changes were obtained from other sources during 1982, and 1988 through 1990.

Selected chimeric fruit were further characterized by dissection, calorimetry, refractometry, titration, and/or HPLC analysis. Rind, flesh, and juice color were determined with a HunterLab Citrus Calorimeter Model D25 (HunterLab, Reston, Va.) (Redd et al., 1986). Juice soluble solids content and acidity were determined by refractometry and titration, respectively, using standard procedures (Redd et al., 1986).

Peel samples from one dark-orange-sectored 'Hamlin' fruit were prepared for chromatographic analysis: Eight disks (1.6 $\mathrm{cm}$ in diameter) were cut from both the normal and dark orange (a deeper color appearing to have more orange pigmentation) sectors of the fruit peel using a cork borer and then stored at - 10C until analysis. After thawing, the disks were washed with hexane to remove the cuticular wax, finely minced using a scalpel, and macerated in $20 \mathrm{ml}$ of methanol (MeOH) using a Tekmar Tissumizer (Tekmar Co., Cincinnati). The suspension was allowed to settle and the supernatant saved. The residue was resuspended in $10 \mathrm{ml}$ of $\mathrm{MeOH}$ with the Tissumizer, allowed to settle, and the supernatant added to the original $\mathrm{MeOH}$ extract. The residue was washed once more with $10 \mathrm{ml}$ of $\mathrm{MeOH}$ as above. The combined $\mathrm{MeOH}$ extract was centrifuged and eluted through a C-18 Sep-Pak (Waters Associates, Milford, Mass.) that had been conditioned with $\mathrm{MeOH}$. Carotenoids were eluted from the Sep-Pak using a mixture of 50 methylene chloride : 50 acetonitrile $(\mathrm{v} / \mathrm{v})$. The solvent was removed under vacuum using a rotary evaporator, redissolved with $1.8 \mathrm{ml}$ of 50 methylene chloride :50 acetonitrile, and transferred to an amber vial.

Chromatographic analysis was completed under the following conditions: The solvent gradient was generated using a PerkinElmer (Norwalk, Corm.) Model 410 quaternary gradient pump. Carotenoids were separated using an Analytichem (Harbor City, Calif.) $5-\mu \mathrm{m} \mathrm{C}-18$ column, $4.6 \mathrm{~mm}$ id. $\times 25 \mathrm{~cm}$. Chromatographic and spectral data were obtained from a Waters Associates Model $990+$ photodiode array detector. Injection was accomplished using a Hewlett Packard (Palo Alto, Calif.) 1050 autosampler. Flow rate was $1.0 \mathrm{ml} \cdot \mathrm{min}^{-1}$, and injection volume was $50 \mu \mathrm{l}$. Solvent composition varied with time as indicated in Table 1. Initial solvent conditions were established with a 2min gradient and a 15-min equilibrium delay before the next injection.

Seeds were extracted from beneath mutant and normal rind sectors of some fruit and were planted in soilless potting mix. Aborted seeds or undeveloped ovules were excised from beneath mutant and normal rind sectors, surface sterilized (1\% solution of sodium hypochlorite), and placed on MT basal medium (Murashige and Tucker, 1969) supplemented with 500 mg malt ex-
Table 1. Solvent composition for HPLC analysis of citrus fruit rind.

\begin{tabular}{lccccc}
\hline \hline & \multicolumn{4}{c}{ Final composition (\%) } & \\
\cline { 2 - 5 } $\begin{array}{l}\text { Time } \\
(\mathrm{min})\end{array}$ & Methanol & Acetonitrile & Hexane & $\begin{array}{c}\text { Methylene } \\
\text { chloride }\end{array}$ & $\begin{array}{c}\text { Gradient } \\
\text { form }\end{array}$ \\
\hline $0-10$ & 15 & 74 & 4 & 7 & --- \\
$10-15$ & 10 & 77 & 6 & 7 & Linear \\
$15-35$ & 5 & 65 & 10 & 20 & Linear \\
$35-45$ & 5 & 50 & 10 & 35 & Linear \\
$45-47$ & 0 & 0 & 20 & 80 & Linear \\
$47-65$ & 0 & 0 & 20 & 80 & --. \\
$65-67$ & 15 & 74 & 4 & 7 & Linear \\
\hline
\end{tabular}

tract/liter in vitro (Starrantino and Russo, 1980). A small percentage of the cultured explants from most fruit produced viable embryos. Embryos that germinated were transferred to soilless potting mix. Ploidy levels of seedlings from gigas-sectored fruit were determined by counting chromosomes in root tip or young leaf cells stained as described by Gmitter et al. (1990).

\section{Results and Discussion}

Fruit sector chimeras were readily recovered in the packinghouse from all eight citrus cultivars examined. Frequencies of chimeric fruit in all cultivars were low (Table 2), as would be expected of mutations, and similar to those previously reported (Lindgren and Sinclair, 1941). However, a much larger volume of fruit was examined at the packinghouse than possible in orchard studies. A total of 2742 chimeric fruit were recovered from packinghouses during the 1988-89 frequency study. Chimeric fruit from number 2 and eliminations categories were collected separately for the cultivars Orlando, Pineapple, Redblush, and Murcott. More chimeras were recovered from the eliminations (858) than from the number 2 grade (678). However, the types of chimeras recovered from the two categories were similar (data not presented), and both appear to be sources of potentially valuable mutations.

The three sweet orange cultivars had considerably greater frequencies of chimeric fruit $(0.082 \%$ to $0.197 \%)$ than were found in the two grapefruit cultivars $(0.017 \%$ and $0.041 \%)$. The mandarin hybrids were most variable, with the greatest ('Orlando'), the mean ('Temple'), and the lowest ('Murcott') frequencies of fruit sector chimeras among all cultivars examined.

Frequency of chimeric fruit obtained from four packinghouse samples of 'Hamlin' fruit (eliminations category only) were 145 in 399,000; 142 in 360,000; 98 in 220,00; and 82 in 211,000; representing $0.036 \%, 0.039 \%, 0.045 \%$, and $0.039 \%$, respectively. The first three of these samples were from fruit harvested in one grove and the fourth sample was from a second grove. The similar chimera frequencies in all four samples prompt the question of whether chimera frequency may be determined by genotype.

Many different types of sector mutations were observed in chimeric citrus fruit (Figs. 1-5). Alterations in sector rind color were most common. Black, brown, green, yellow, white, dark red, and dark orange mutant sectors were observed. Some rind color changes may be of potential value for cultivar improvement if plants can be obtained that produce nonchimeric fruit of the mutant phenotype. Dark red grapefruit and dark orange sweet orange or tangelo fruit are highly valued; a mutant producing darker fruit, but otherwise identical to the original cultivar, would be of major value. Fruit were found with dark red or orange rind sectors in five of the seven cultivars examined 
Table 2. Number and frequency of total fruit sector chimeras from eight citrus cultivars.

\begin{tabular}{|c|c|c|c|c|c|c|c|}
\hline \multirow[b]{2}{*}{ Cultivar } & \multirow{2}{*}{$\begin{array}{l}\text { Estimated } \\
\text { sample size } \\
\text { (thousands) }\end{array}$} & \multirow{2}{*}{$\begin{array}{c}\text { Chimeric } \\
\text { fruit } \\
(\%) \\
\end{array}$} & \multicolumn{5}{|c|}{ Fruit with chimeric sectors (no.) } \\
\hline & & & Gigas $^{2}$ & $\begin{array}{c}\text { Red/ } \\
\text { orange }\end{array}$ & Green & Other ${ }^{y}$ & Total \\
\hline Orlando tangelo & 139 & 0.271 & 62 & 1 & 1 & 313 & 377 \\
\hline Valencia orange & 337 & 0.197 & 102 & 19 & 61 & 482 & 664 \\
\hline Pineapple orange & 430 & 0.167 & 108 & 12 & 16 & 584 & 720 \\
\hline Temple tangor & 181 & 0.110 & 21 & 6 & 34 & 139 & 200 \\
\hline Hamlin orange & 399 & 0.082 & 111 & 0 & 16 & 200 & 327 \\
\hline Redblush grapefruit & 161 & 0.041 & 8 & 6 & 7 & 45 & 66 \\
\hline Marsh grapefruit & 117 & 0.017 & 6 & 0 & $\mathbf{0}$ & 14 & 20 \\
\hline Murcott tangor & 519 & 0.009 & 2 & 0 & 3 & 41 & 46 \\
\hline
\end{tabular}

${ }^{\mathrm{z}}$ Gigas $=$ sectors with raised, thickened rind.

yOther = black, brown, yellow, or white sectors, as well as depressed rind or other sector changes.

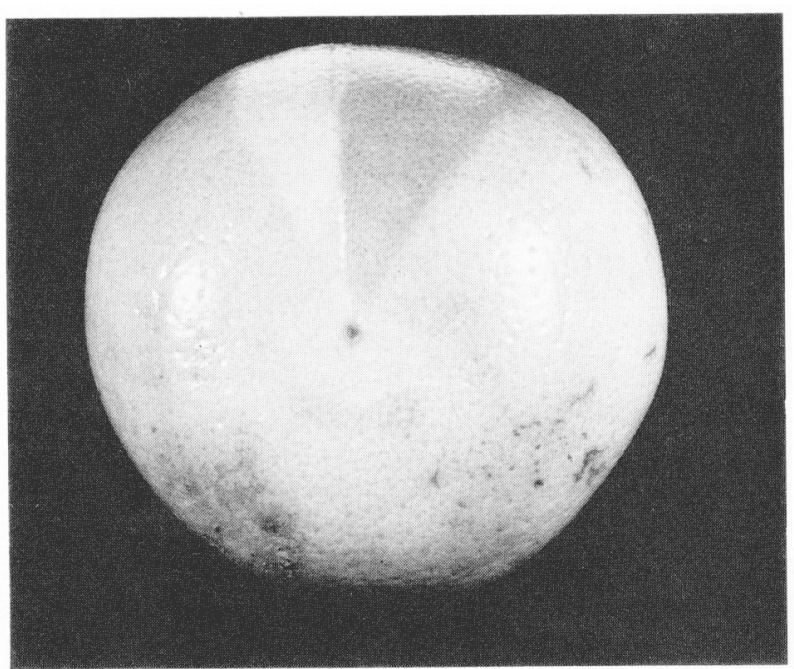

Fig. 1. Dark red and yellow twin mutant sectors on 'Redblush' grapefruit, chimera 2.

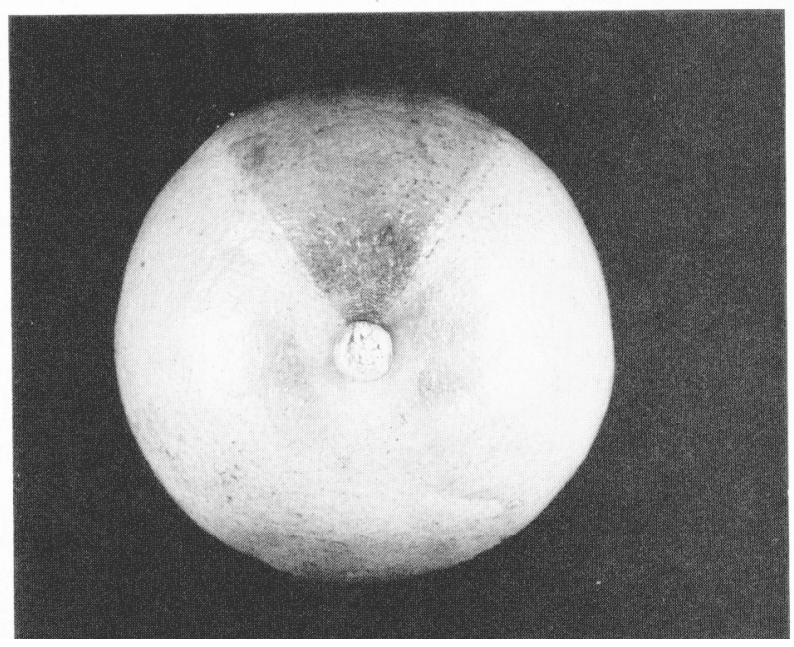

Fig. 2. Dark Orange sector on 'Hamlin' orange, chimera 12.

that have red or orange rind (Figs. 1 and 2; Table 2). Several dark-orange-sectored 'Hamlin' fruit were recovered from other samples not included in Table 2. Rind, flesh, and juice color values of several chimeric fruit clearly demonstrate the degree of some sector color differences. Flesh and juice color were darker in dark-rinded sectors of some 'Redblush' chimeric fruit

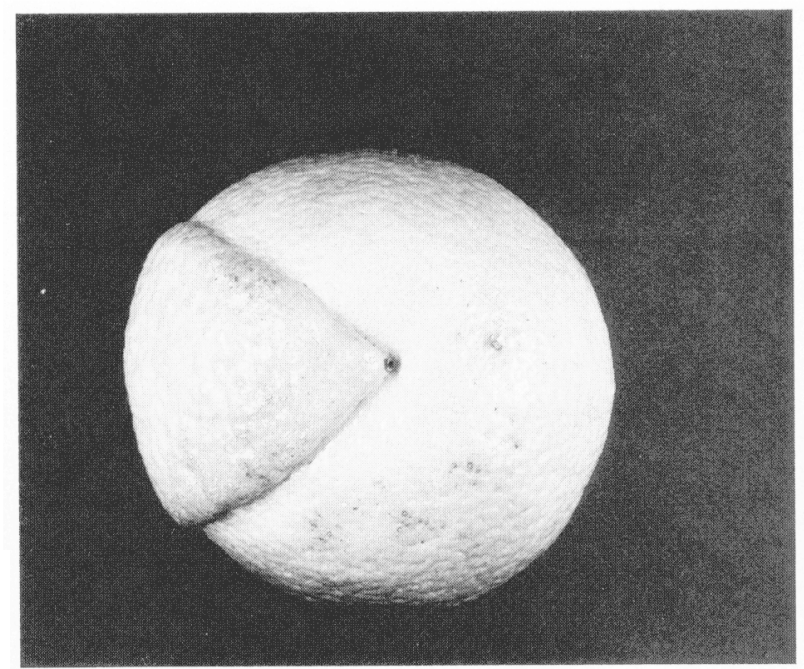

Fig. 3. Gigas sector on 'Valencia' orange fruit.

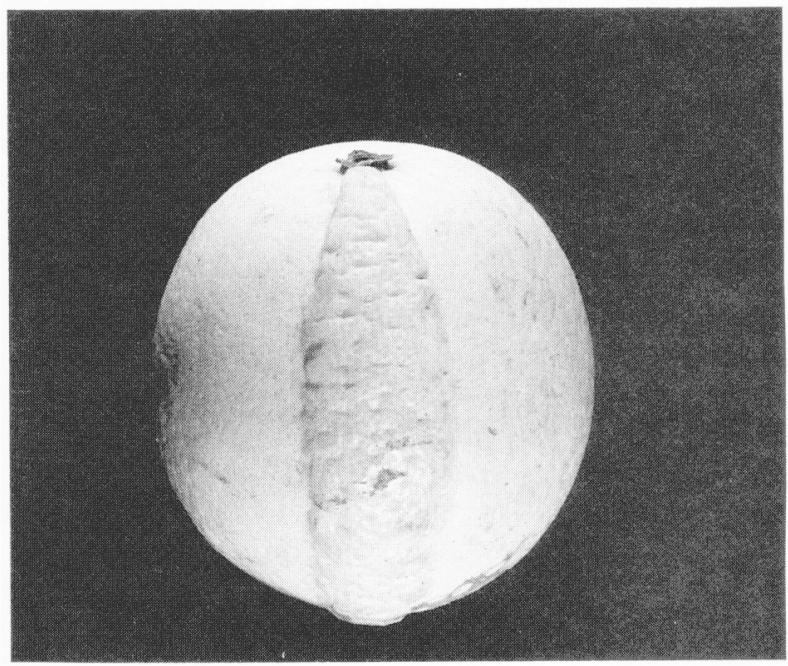

Fig. 4. Gigas sector on 'Hamlin' orange fruit.

(Table 3). The effect on juice color is probably of more significance to the Florida citrus industry than rind color because of the large portion of the production that is used for juice. However, we believe that at least some of the mutations restricted to the rind in the chimeric fruit may influence flesh and juice color if they can be recovered in nonchimeric plants (see discussion of histogenic layers below). 


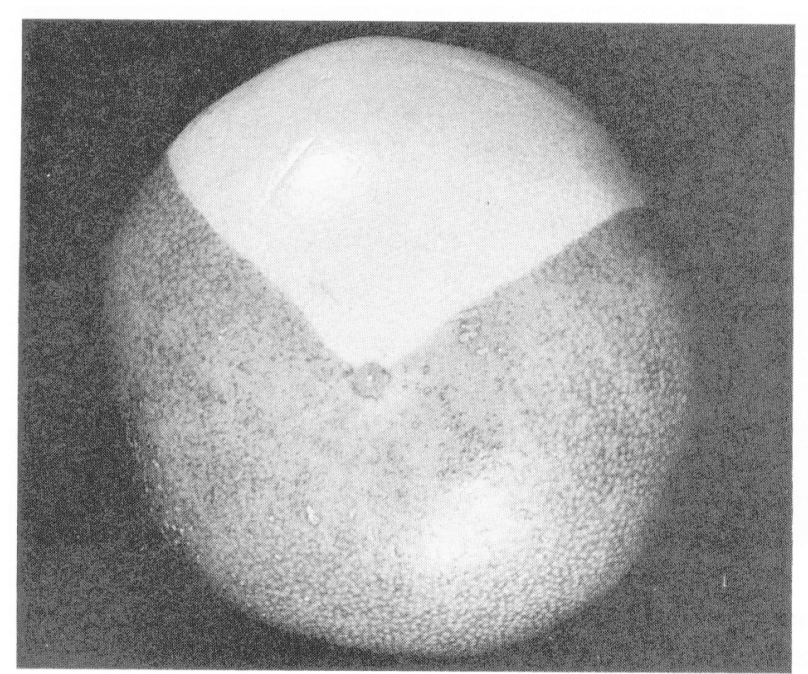

Fig. 5. Clean sector on a grapefruit with severe rind damage of unknown origin. (Photo courtesy of W. Grierson)

'Hamlin' is an early maturing sweet orange cultivar widely planted in Florida but, when grown there, typically lacks the more desirable dark orange peel usually associated with sweet orange. Flesh and juice color in 'Hamlin' fruit are particularly poor and substantially limit the value of the cultivar for juice production. The wide and unusually dark orange sector found on one 'Hamlin' fruit (Fig. 2) appeared to be a favorable mutation and was examined further.

The $a: b$ ratio (a standard measure of the amount of red and orange color in citrus fruit) of the dark orange peel sector on the 'Hamlin' chimera was exactly double that of the normal part of the fruit (Table 3). The peel tissue of the mutant sector contained a higher concentration of carotenoids than the normal sector, as shown by the larger chromatographic peaks (Fig. 6). Because carotenoids may be identified by their characteristic visible absorption spectra, the spectra of the five major peaks in the sample from the mutant sector were compared with the corresponding peaks from the normal section of the fruit (Fig. 6 , inserts). The absorbance maxima for the five peaks were 462 , 450, 454, 458, and $462 \mathrm{~nm}$, respectively. Absorption maxima for peaks 3-5 from the normal peel matched very well with the same peaks for the mutant sector. However, there were appre- ciable differences in both amounts and kinds of pigments found in the first $10 \mathrm{~min}$ of samples from the two sections of the fruit. Peaks 1 and 2 from the mutant sector were found in this region and do not have a good match in the normal section. Although the major differences in the carotenoids of this chimera appear to be quantitative rather than qualitative, the chromatogram indicates the presence of some very polar carotenoids (early peaks) in the mutant sector that do not appear in the normal section. The dark coloration of the chimeric sector was primarily due to a greater concentration of carotenoids rather than from carotenoids of different spectral properties. However, the contribution to improved color of some apparently unique polar carotenoids in the mutant sector is uncertain.

Fruit with green rind sectors were found from each of the cultivars examined except 'Marsh' (Table 2). A green sector may result from a mutation that disrupts or delays the maturation process. A later-ripening selection of an early cultivar would allow a longer harvesting season and could be of substantialvalue. Rind color was more green in the mutant sector of one chimeric navel orange fruit discovered on the tree by chance in 1988. However, flesh color, juice color, and brix : acid ratio were essentially the same for both sectors of this fruit (Table 3 ). At the same time, a sample of normal (nonchimeric) fruit from this navel tree yielded values of $\mathrm{a} / \mathrm{b}=0.43(\mathrm{sD}=0.03)$ for rind color, $\mathrm{a} / \mathrm{b}=0.20(\mathrm{sD}=0.03)$ for flesh color, citrus redness $(\mathrm{CR})=35.4$ for juice color, and 20.0 for brix : acid ratio. These results suggest that the entire chimeric fruit (not just the green sector) was less mature than the normal fruit.

Another common mutation resulted in a sector with thicker rind than normal, termed gigas by us. These mutations were found among all of the cultivars examined (Table 2, Figs. 3 and 4). At least some gigas sectors appear to be cytochirneras. Seedlings recovered from gigas sectors of one 'Orlando' and three 'Valencia' chimeric fruit were tetraploid $(2 n=4 x=36)$. No viable seeds were found in normal sectors of these fruit, but seedlings obtained from normal sectors of other gigas-chimeric 'Valencia' and 'Orlando' fruit were diploid $(2 \mathrm{n}=\mathbf{2 x}=18)$. Ploidy level of young seedlings from 'Valencia' gigas chimeras usually and easily could be ascertained visually: Tetraploids had darker green, thicker leaves and stouter stems and frequently had the first two leaves fused together at the base. For polyembryonic cultivars (e.g., 'Orlando' and 'Valencia'), tetraploid seedlings were expected to be of nucellar origin (nonzygotic)

Table 3. Internal and external characteristics of mutant and normal sectors of four chimeric citrus fruit. ${ }^{z}$

\begin{tabular}{clcccc}
\hline \hline $\begin{array}{c}\text { Type of citrus } \\
\text { (date recovered; } \\
\text { Fig. no.) }\end{array}$ & $\begin{array}{c}\text { Color of } \\
\text { sector }\end{array}$ & $\begin{array}{c}\text { Rind color } \\
\text { a/b }\end{array}$ & $\begin{array}{c}\text { Flesh color } \\
\text { a/b }\end{array}$ & $\begin{array}{c}\text { Juice color } \\
\text { (CR) }\end{array}$ & $\begin{array}{c}{ }^{\circ B} \text { Brix : acid } \\
\text { ratio }\end{array}$ \\
\hline $\begin{array}{c}\text { Navel orange 1 } \\
\text { (Dec. 1988) }\end{array}$ & $\begin{array}{l}\text { Green } \\
\text { Normal }\end{array}$ & $\begin{array}{c}-0.07(0.18) \\
0.41(0.13)\end{array}$ & $\begin{array}{c}0.08(0.04) \\
0.15(0.07)\end{array}$ & $\begin{array}{l}26.5 \\
29.8\end{array}$ & 11.7 \\
$\begin{array}{c}\text { Hamlin orange 12 } \\
\text { (Nov. 1989; Fig. 2) }\end{array}$ & $\begin{array}{l}\text { Dark orange } \\
\text { Normal }\end{array}$ & $0.74(0.03)$ & ND & ND & ND \\
Redblush grapefruit 2 & No.37(0.05) & ND & ND & ND \\
(Dec. 1988; Fig. 1) & Dark red & $0.72(0.04)$ & $1.25(0.14)$ & 31.5 & 7.7 \\
Redblush grapefruit 35 & Normal & $0.13(0.06)$ & $0.77(0.08)$ & 17.7 & 7.0 \\
(Nov. 1989) & Dark red & $0.92(0.16)$ & $1.44(0.32)$ & ND & 10.0 \\
& Normal & $0.19(0.16)$ & $0.86(0.20)$ & ND & 10.5 \\
\hline
\end{tabular}

$\mathrm{z}_{\mathrm{a} / \mathrm{b}}=\mathrm{a}$ standard measure of the amount of red and orange color in citrus fruit (Redd et al., 1986);

${ }^{\circ} \mathrm{Brix}=$ total corrected Brix (Redd et al., 1986); CR = citrus redness by Hunter colorimeter (Ting and

Rouseff, 1986); ND = no data. Numbers in parentheses represent SD. 


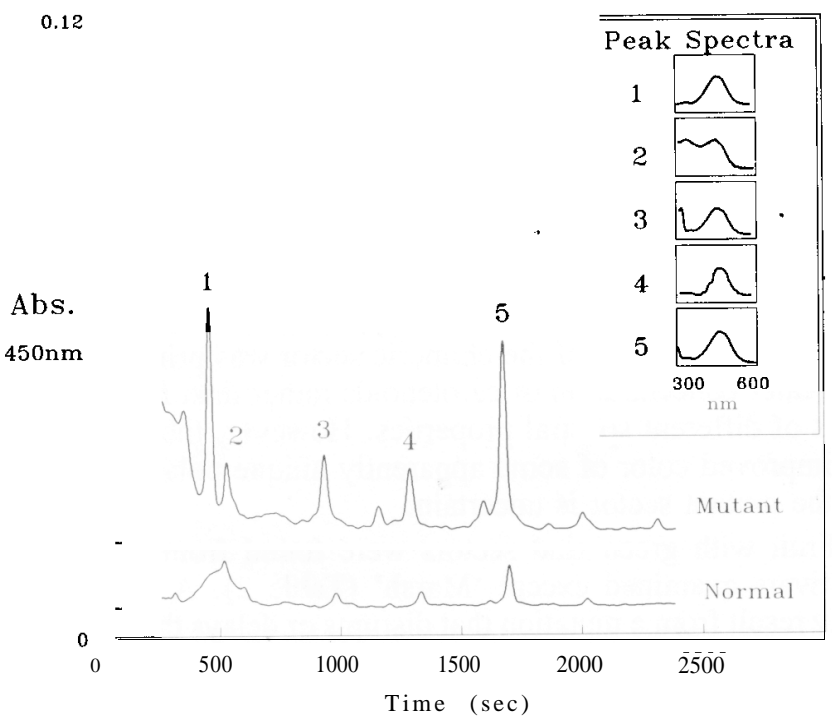

Fig. 6. Chromatography of dark orange (mutant) and normal rind tissue from 'Hamlin' orange chimera 12 with absorption spectra of the five major peaks from the mutant.

and the result of somatic doubling (autotetraploids). This expectation was corroborated by identical isozyme banding patterns in diploid trees and tetraploid seedlings (data not shown). Gigas fruit sector chimeras appear to be an easily accessible source of autotetraploids for many, if not all, polyembryonic citrus genotypes. Tetraploids of commercially important cultivars are of significant interest because of their potential use as parents in breeding for seedless triploid selections (Soost and Cameron, 1968, 1980). Seedlings from gigas sectors of monoembryonic cultivars (e.g., 'Temple') likely would be zygotic and, perhaps, triploid, although this has not yet been confirmed experimentally.

Chimeric fruit with sectors appearing to have different susceptibility to rind damage caused by pests or diseases were also recovered. These made up a substantial proportion of the chimeric sectors classified as black or brown. In most cases, it appeared that normal fruit had very little damage and the mutant sectors of the fruit rind were more susceptible than normal. However, chimeric fruit with sectors distinguished by clear differences for some types of rind damage have been previously observed (W. Grierson, personal communication) (Fig. 5). Mutations of this type are of interest as a potential source of cultivars with increased resistance to pests or diseases. Greater success in finding potentially resistant mutant sectors might be obtained by searching among fruit from orchards grown with minimal pest and disease control and destined for processing.

The basis of some fruit sector chimeras maybe somatic segregation, because occasionally two adjacent, contrasting sectors (twin sectors) were observed, such as dark red and light yellow sectors on normal slightly pink 'Redblush' grapefruit rind (Fig. 1). In two samples of chimeric fruit (data on several cultivars combined), 12 of $150(8 \%)$ and 13 of $150(8 \%)$ had twin sectors. In other cases, sector chimeras may result from spontaneous polyploidization or other genetic mutations. Albino plants were obtained from the dark red rind sector of two 'Redblush' chimeric fruit, while plants obtained from the normal part of the same fruit were green (Fig. 7). All seedlings obtained from some similar red-sectored 'Redblush' chimeras appear normal in vegetative growth but may possess less deleterious genetic mutations.

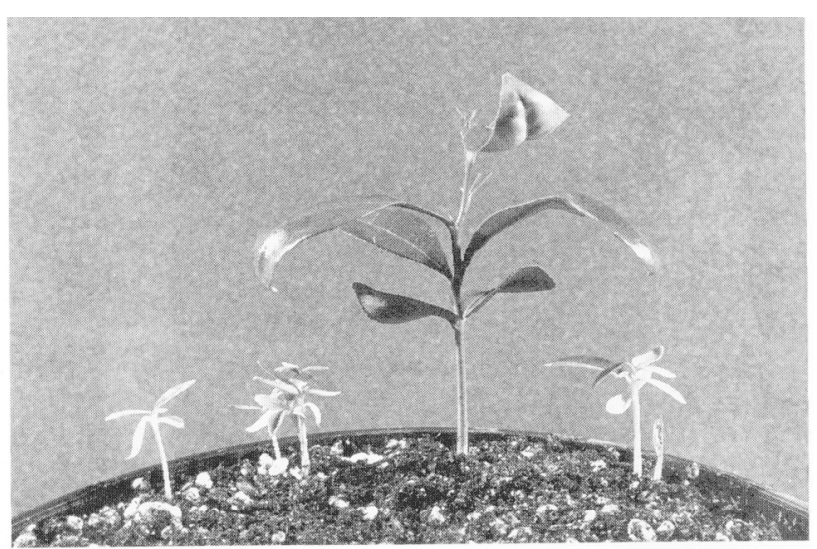

Fig. 7. Albino seedlings obtained from the dark red sector of a 'Redblush' grapefruit chimera and one normal seedling from the normal sector of the same fruit.

Some fruit sector chimeras may be sectorial, having all cells within the affected sector of the mutant type (Cameron and Frost, 1968; Iwamasa et al., 1977). However, the lack of dark flesh color in some dark-rinded chimeric fruit may be caused by the restriction of the mutation to the L-II layer; the flesh in these mericlinal chimeric fruit remains genetically and calorimetrically normal because it is derived from unaffected L-I tissue (Soost and Cameron, 1975). Citrus nucellar embryos are derived from the L-II layer (Soost and Cameron, 1975), and rind mutations that are mericlinal chimeras should be recovered in seedlings.

Width of chimeric sectors varied from $<1 \mathrm{~mm}$ to almost the entire fruit and may be influenced by the time of development when the mutation occurred or the effect of the mutation on tissue growth. Boundaries of chimeric rind sectors aligned perfectly with internal fruit septa in some cases, but more often there was no alignment. In two samples of chimeric fruit (data for several cultivars combined), 19 of 131 (15\%) and 22 of 120 $(18 \%)$ had peel sectors that lined up with septa inside the fruit. It is unclear whether this characteristic will have any bearing on type of chimera (mericlinal or sectorial) or likelihood of mutant recovery. We have obtained tetraploid seedlings from both aligned and unaligned gigas chimeras.

We have demonstrated the value of gigas fruit sector chimeras as a source of autotetraploid seedlings from commercial polyembryonic citrus cultivars. The reports of increased gigas sector formation following cyanide fumigation (Sinclair and Lindgren, 1943) and Lorsban application (M.L. Arpaia, personal communication) suggest that this phenomenon may be manipulated to maximize polypoid recovery. Tetraploids are of significant value as parents in breeding triploid seedless hybrids (Soost and Cameron, 1968, 1980). Observation of several other types of sector mutants that appear to be superior to the normal genotype points out the potential usefulness of this resource. Mutant oranges and mandarins with dark orange rind would greatly enhance visual appeal of fresh fruit from many citrus cultivars and might reduce the need for ethylene degreening (McComack and Wardowski, 1977) and application of dye for consumer acceptante (Kaplan, 1986). Selections with increased flesh and juice color or altered maturity date could significantly improve marketability of Florida citrus. Finally, pest- and disease-resistant sector chimeras may have potential for the production of selections that yield high-quality fruit without pesticide application. 


\section{Literature Cited}

Cameron, J.W. and H.B. Frost. 1968. Genetics, breeding, and nucellar embryony, p. 325-370. In: W. Reuther, L.D. Batchelor, and H.J. Webber (eds.). The citrus industry. vol. 2. Univ. of California Press, Berkeley.

Frost, H.B. 1943. Genetics and breeding, p. 870-888. In: H.J. Webber and L.D. Batchelor (eds.). The citrus industry. vol. 1. Univ. of California Press, Berkeley.

Frost, H.B. and R.K. Soost. 1968. Seed reproduction: Development of gametes and embryos, p. 290-324. In: W. Reuther, L.D. Batchelor, and H.J. Webber (eds.). The citrus industry. vol. 2. Univ. of California Press, Berkeley.

Gmitter, F. G., Jr., X.B. Ling, and X.X. Deng. 1990. Induction of triploid Citrus plants from endosperm calli in vitro. Theor. Appl. Genet. 80:785-790.

Hearn, C.J. 1986. Development of seedless grapefruit cultivars through budwood irradiation. J. Amer. Soc. Hort. Sci. 111:304-306.

Hensz, R.A. 1981. Bud mutations in citrus cultivars in Texas. Proc. Intl. Soc. Citriculture Tokyo. 1:89-91.

Hodgson, R.W. 1967. Horticultural varieties of citrus, p. 431-591. In: W. Reuther, L.D. Batchelor, and H.J. Webber (eds.). The citrus industry .vol. 1. Univ. of California Press, Berkeley.

Iwamasa, M., M. Nishiura, N. Okudai, and D. Ishiuchi. 1977. Characteristics due to chimeras and their stability in citrus cultivars. Proc. Intl. Soc. Citriculture Orlando. 2:571-574.

Kaplan, H.J. 1986. Washing, waxing, and color-adding, p. 379-395. In: W .F. Wardowski, S. Nagy, and W. Grierson (eds.). Fresh citrus fruits. AVI, Westport, Conn.

Lindgren, D.L. and W.B. Sinclair. 1941. The ridging of citrus fruits as influenced by fumigation of citrus trees with $\mathrm{HCN}$. J. Econ. Entomol. 34(3):477.

McCornack, A.A. and W.F. Wardowski. 1977. Degreening Florida citrus fruit: Procedures and physiology. Proc. Intl. Soc. Citriculture, Orlando. 1:211-215.

Mendel, K. 1981. Bud mutations in citrus and their potential commercial value. Proc. Intl. Soc. Citriculture Tokyo, 1:86-89.
Murashige, T. and D.P.H. Tucker. 1969. Growth factor requirements of citrus tissue culture. Proc. First Intl. Citrus Symp. 3:11551161 .

Redd, J. B., C.M. Hendrix, Jr., and D.L. Hendrix. 1986. Quality control manual for citrus processing plants. vol. 1. Regulation, citrus methodology, microbiology, conversion charts, tables, other. Intercit, Safety Harbor, Fla.

Russo, F., B. Donini, and A. Starrantino. 1981. Mutagenesis applied for citrus improvement. Proc. Intl. Soc. Citriculture, Tokyo. 1:6870.

Shamel, A.D. 1943. Bud variation and bud selection, p. 915-952. In: H.J. Webber and L.D. Batchelor (eds.). The citrus industry. vol. 1. Univ. of California Press, Berkeley.

Sinclair, W.B. and D.L. Lindgren. 1943. Ridges and sectors induced in the rind of citrus fruits by fumigation with hydrocyanic acid. Plant Physiol. 18:99-106.

Soost, R.K. and J.W. Cameron. 1968. Tree and fruit characters of citrus triploid crosses. Hilgardia 31:569-579.

Soost, R.K. and J.W. Cameron. 1975. Citrus, p. 507-540. In: J. Janick and J.N. Moore (eds.). Advances in fruit breeding. Purdue Univ. Press, West Lafayette, Ind.

Soost, R.K. and J.W. Cameron. 1980. 'Oroblanco', a triploid pummelo-grapefruit hybrid. HortScience 15:667-669.

Soule, J. and W. Grierson. 1986. Maturity and grade standards, p. 23-48. In: W.F. Wardowski, S. Nagy, and W. Grierson (eds.). Fresh citrus fruits. AVI, Westport, Conn.

Starrantino, A. and F. Russo. 1980. Seedlings from undeveloped ovules of ripe fruits of polyembryonic citrus cultivars. HortScience 15:296297

Stewart, I., G.D. Bridges, A.P. Pieringer, and T.A. Wheaton. 1975. 'Rohde Red Valencia', an orange selection with improved juice color. Proc. Fla. State Hort. Soc. 88:17-19.

Ting, S.V. and R.L. Rouseff. 1986. Citrus fruits and their products: Analysis and technology. Marcel Dekker, New York.

Toxopeus, H.J. 1933. Some cases of bud variation in Citrus observed on Java. Genetics 15:241-252. 